\title{
Analysis of Printing Pressure Using Density Measurements of Printed Ink
}

\section{Ramesh R Dendge}

1. Lecturer in Printing Technology, Government Institute of Printing Technology Mumbai, (MS), India; e-mail: rameshdendge@ rediffmail.com

Article history :

Received : $15^{\text {th }}$ May, 2019

Accepted : $10^{\text {th }}$ July., 2019

DOI : 10.18090/samriddhi.v11i01.6

Keywords : Lithographic sheet-fed offset, Cyan ink, uncoated paper, Densitometer, Statistic.

*Corresponding author :

Ramesh R Dendge

e-mail : rameshdendge@ rediffmail.com

\begin{abstract}
In process-color lithographic sheet-fed offset printing the uniformity of printing pressure is critical in achieving consistent print quality. The variations in printing pressure at blanket and impression cylinder nip affect the resultant print density of process colors. The variations in printing pressure are observed not only within the print run but also in the print area of the sheet. The printing pressure is the function of machine engineering, blanket cylinder covering material, substrate, and thickness of image carrier, packing materials used in packing of blanket and plate cylinder. Many printers, even today, use a feeler gauge to judge the level of printing pressure at two or three places along with the blanket and impression cylinder nip. The conventionalfeeler gauge method yields qualitative information and considers a very smaller portion of the print area. In this experimental work, the densitometry is used to devise an alternative subjective method to give information about the levels of printing pressure across the print area. The image equalling print area is divided into uniformly spaced small patches and one thousand sheets uncoated paper are printed with cyan color on large format offset printing machine. Three sheets, $101^{\text {th }}, 501^{\text {th }}$, and $901^{\text {th }}$, representing the start, middle and the end of the print run are selected. Out of each identified sheets, three patches are selected from left middle and right columns giving a total nine locations from across the print area. The reflection densities, of nine cyan patches uniformly covering the print area, are measured using electronic densitometer for each of the sheets and tabulated. This approach, involving statistics, is aimed at providing a quantitative tool to analyze printing pressure variation across the print area and within the print run.
\end{abstract}

\section{INTRODUCTION}

$\mathrm{L}$ ithographic offset printing technology is an impact-based printing technology that needs printing pressure between 0.8 to $2.0 \mathrm{MPa}$ to effectively transfer ink film from image carrier to the paper or other substrate through blanket cylinder (Helmut, 2008). This is an important design consideration helps produce necessary contact pressure at the nips formed between plate and blanket and blanket and impression cylinder.
In addition the similar contact pressure is also required between different rollers of inking and dampening unit of lithographic offset printing machine. The ink film thickness transferred on to the substrate is determined by the pressure setting between, plate-blanket and blanket-impression cylinders, and rollers from inking and dampening systems. The higher printing pressure levels enable larger area of substrate in contact with inked image carrier. The visible result of different pressure settings is observed in the print taken on the 
intended substrate. Like all other impact based printing technologies lithographic offset printing technology demands uniform printing pressure across the print area to produce consistent print quality.

Printers using medium to large-sized lithographic offset printing machines, use feeler gauge to judge the pressure between rollers. This method is objective and qualitative involving application of feeler gauge at two or three positions along the nip. Besides this the dimensions of feeler gauges generally used do not cover larger length formed by the contact between plate-blanket and blanket-impression cylinders. Thus when used along the plate-blanket and blanket-impression cylinder nips, the feeler gauge method can limit its information only for the selected part of total contact. As the method does not give output in quantitative form the printer does not get any help to prepare database and take scientific and studied corrective action. Furthermore, this method does not let printer notice smaller difference in pressure that may result in density variation in printed ink. Another method of determining printing pressure is the use of pressure sensitive two-sheet prescale film. This film is placed in blanket and impression cylinder nip. When the printing pressure is applied, microcapsules on the first sheet rupture and colour forming material from it reacts with colour developing material of other sheet. The density value of the colour is a measure of the generated printing pressure levels at different positions along the nip but lacked information about printing pressure levels across the contact area formed by the contacting rolls or cylinders. The printing pressure in the blanket and impression cylinder nip is also estimated using a piezoelectric transducer fitted on one of the cylinders or in a rolling calendar nip. This method was found to be limited to pressure measurement in positive regions only. Successful measurement of printing pressure along printing nip were carried using employing rod, connected to measuring chamber, with small holes drilled into it. This information could not offer reliable estimate of printing pressure at the exit of the metering nip.

A considerable work has been done in the area of investigation of printing pressure variation on sheet-fed lithographic offset press. Agnieszka, J (2014, p. 99-105) used experimental design involving three printing pressure levels exercised on gloss-coated and matte-coated papers. This experiment made use of blanket having equal hardness of 82 shores and applied dynamic printing pressure measurements at slow speed between blanket and impression cylinders using a Nip Control Pressure Indicator. Three printing pressure levels were applied varying packing thickness between plate and blanket cylinder. It was observed that gloss and matte-coated papers gave rise to different printing pressure during printing. Rastko, M (2014, p. 375-382)'s experimental work provided equation that determines the dependence of pressure on cylinder strain and the contact zone width expressed in terms of radii of contacting cylinders. This equation was recommended for setting the contact zone width correctly. This experiment did not involve use of printing of solid or line images to assess the effect of affectivity of suggested method. Agnieszka, J ( 2013, p. 10-15) printed ECI2000V CMYK PM 5.0.5 test-chart, at three different printing pressures to measure colour gamut volume and colour difference using Gretag Macbeth Spectrophotometer and Spectrolino instruments. This experiment underlined the importance of the optimum printing pressure but did not provide method to assess printing pressure levels across the print area. Rastko, M (2013, p. 171-173) tried to propose method for determining optimum printing pressure level. This experiment 
printed test image, consisting six identical rows, on coated and uncoated papers on offset printing machine by simultaneously mounting six underlay sheets on blanket cylinder. Layout of every row of test image was formed by segments of solid value, two scales from $10 \%$ to $100 \%$ oriented in opposite directions, the tonal values from $1 \%$ to $5 \%$ and $95 \%$ to $99 \%$ as well as horizontal and vertical microclines and other graphic control elements. This experiment provided relationship between printing pressure level as generated by underlay and observed optical density. This experiment using solid tonal segment at six places covered considerable print area but did not provide information regarding printing pressure level variation along printing nip and in the circumferential direction. Hansson, R. (2012, p. 1-4) suggested use of electronic measurement in blanket/blanket and blanket/plate nips for pressure measurements in $\mathrm{N} / \mathrm{cm}^{2}$ This technique gave actual quantification of pressure but did not recommend the same measurement to systematically measure values for entire print area. Junghong, G (2011, p. 321-324) provided basis to discuss advantages of pneumatic on-off pressure mechanism of offset press without information about finite distribution of pressure in print area.Shuqin, W. (2009, p. 342344) worked on detection experiment of impression force was carried out studied on the contact area between the impression cylinder and the blanker cylinder of an offset sheeted printing machine. This experimental work highlighted the importance of the nature of the blanket, the substrate and other materials on uniformity of printing pressure nut did not expand area under consideration from contact nip to total printable area of printing press. Yung, C. (1997, p. 58-70) investigated effect of plate/blanket and blanket/plate pressure on dot gain besides fountain solution $\mathrm{pH}$, paper
types.Alexander M. (1991, p. 33-50) analysed the behaviour of compressible and incompressible blankets under varying tension and packing thicknesses was studied. These research work established statistical significance in difference between dot gain values arising from tensioning of blanket and packing thickness but efforts were mainly directed towards studying effects of printing pressure and not the measurement of pressure. Hong-guang, S. (2016, p. 1) used different printing pressures at constant speed to study relationship between printing pressure and ink transfer in CMYK offset printing. Menges M. (1995, p. 1-8) explained basic theory behind crowning of industrial rollers and elaborated static and dynamic nip behaviour during impression. This work deeply explained deflection phenomena in the rollers and behaviour of rollers under deflection. This work concentrated on nip area and did not explained profile of pressure across surface area rollers.

As against semiautomatic sheet-fed lithographic offset printing presses the advanced printing machines use the closed loop system to measure the density of inks from the printed sheet and compute the difference and generates the corrective signals enabling inking system to meter ink flow according along the width of press. But this system also measure density values along either leading or trailing edge of the printed sheet. The volume and scope of label and industrial printing using offset printing technology is increasing even among the printers using semiautomatic sheet-fed offset printing press and therefore assessment of printing pressure across the print area requires a method that can quantify the data relating to printing pressure levels and produce an information regarding an usefulness of machines in label and industrial printing. 
The discussion on experimental work aimed at measuring the print consistency is divided in five sections of this report.

The working principle, construction and characteristics of sheet fed lithographic offset printing technology and the relevant literature are discussed in this section. The information on materials and parameters as identified for the experimental work is presented in the second section along with adequate detailing of experimental set-up. The third section elaborates observation and subsequent results with the help of appendices and figures. In fourth section, observation and results are further discussed with regard to efficacy and limitations of the experimental set- up. The final section combines the observation, result and discussion to draw conclusions.

\section{METHODS}

During the experimental work, the lithographic offset press of $18 \times 23$ inch size known to be involved in frequent process color printing was identified. The actual working condition regards to automation, usage of consumable, operating methodology, quality practice and prevalent machine speed was kept unchanged. The identified machine used conventional inking and dampening systems.

Patches of $2 \times 2 \mathrm{~cm}$ size are imaged on the presensitised plate using conventional photomechanical process. The uncoated paper of 70 GSM was used as a substrate along with magenta process ink to print a lot of 1000 sheets wherein each printed sheet consisted of 22 rows and 35 columns of solid magenta patches. Magenta process ink is selected, as measurement variable, because it produces good image contrast on a white background when compared to, especially, yellow process ink. From printed lot $101^{\text {st }}, 501^{\text {st }}$ and $901^{\text {st }}$ sheets were selected to measure the density of patches in $1^{\text {st }}, 11^{\text {st }}$ and $22^{\text {nd }}$ columns and $1^{\text {st }}, 17^{\text {th }}$ and $35^{\text {th }}$ rows. The reflection density measurement was carried out using color densitometer.

\section{RESULTS}

Fig. 1-6 represent plots, of the cyan patch against its reflection density, drawn from density readings tabulated in appendices $\mathrm{A}$ and $\mathrm{B}$. Appendix A shows patch-wise cyan density for top middle and bottom rows, whereas appendix B shows patch-wise cyan density for left middle and right columns of $101^{\text {th }}, 501^{\text {th }}$, and $901^{\text {st }}$ sheets. Plots in Fig. 1-3 show printing pressure variation across the width of the printing press and Fig. 4-6 highlight it in the circumferential direction of the printing press. The cyan density behavior, from patch 1 to 35 , across the width of the press as shown in Fig. 1-3 is the same and with a change in density values and Fig. 4-6. In comparison, the density behavior, from patch 1 to 22 , in the circumferential direction of the press as shown in Fig. 4-6 is showing variations. The curves representing $1^{\text {st }}, 11^{\text {th }}$ and $22^{\text {nd }}$ columns are not as overlapping or close, as they are in case of curves of $1^{\text {st }}, 17^{\text {th }}$ and $35^{\text {th }}$ rows shown in Fig. 1-3. Among the columns, the $35^{\text {th }}$ column is showing increased density and the $17^{\text {th }}$ column is showing the lowest density values. In both, across and circumferential directions the density values are stabilized with a print run with little change in density distribution.

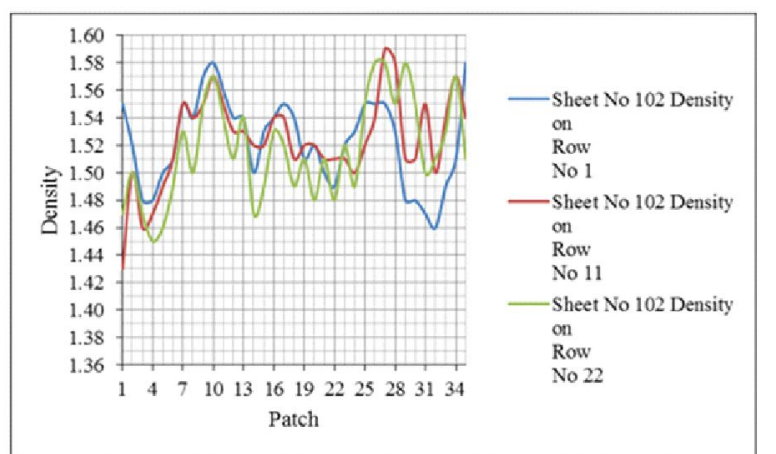

Fig.1: Plot of the cyan patch against its reflection density. 


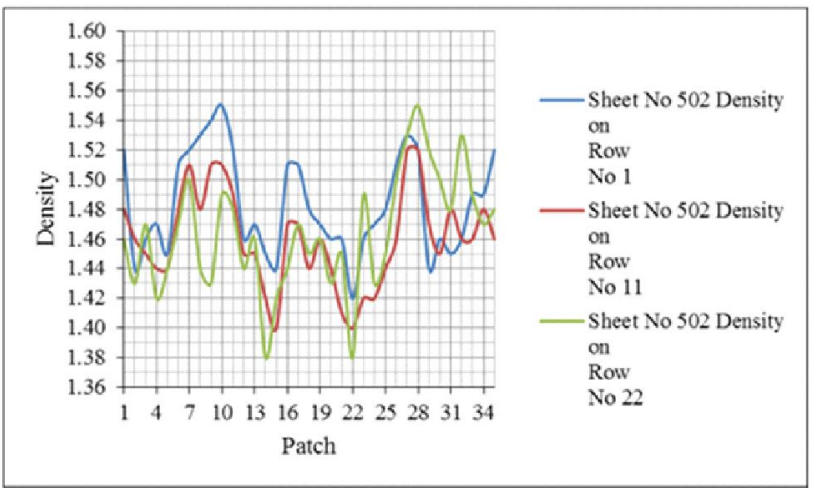

Fig.2: Printing pressure variation across the width of the printing press

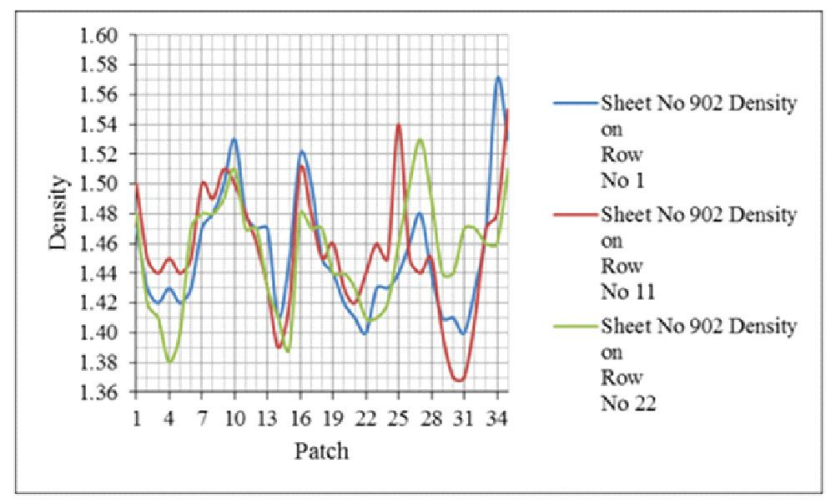

Fig.3: Cyan density behaviour



Fig.4: Circumferential direction of the printing press

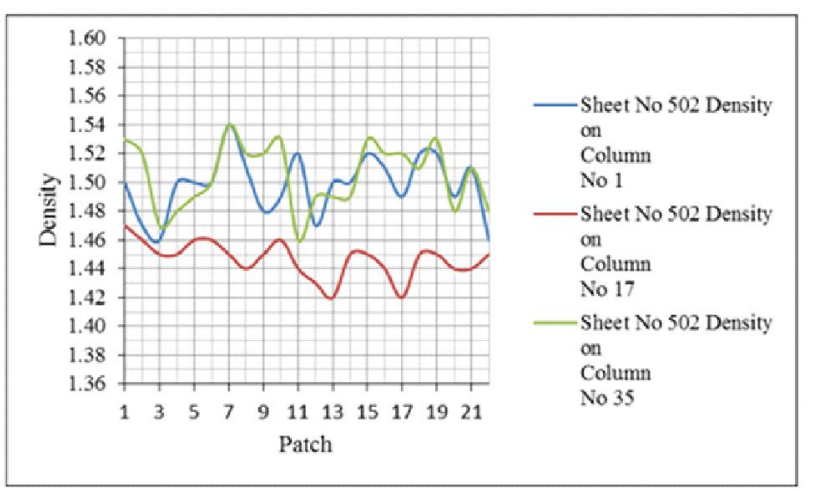

Fig.5: Lowest density values.



Fig.6: Patch-wise cyan density for top middle and bottom rows

\section{DISCUSSION}

Nowadays lithographic offset printing technology is also used to print labels in multiple formats. Besides process colors, label involves the printing of logo, symbol or house color. In such cases, the shade achieved during printing must remain within acceptable limits to minimize wastage and rejection. When the entire print area involves process color printing tonal and gray balance may vary across the print area but such variation is not as noticeable and measurable as is the case for the label printed in multiple formats. During label printing in multiple formats, the shade variation beyond acceptable limit adds to rejection and wastage especially when label predominantly consist of special or solid color printing. The shade resulted during printing is the function of effective printing pressure at the point of contact between blanket and impression cylinders. All impact based printing technologies to some extent show variation in printing pressure. Although this experimental work has taken up the case of lithographic offset printing technology the other conventional printing technologies can also use the method to assess the evenness of shade across the printable area. 


\section{CONCLUSION}

From the above trials, it can be concluded that ink film thickness variation along the contact line and across the contact area between blanket and impression cylinder has many levels at different instances of time. The experimental approach of dividing blanket and impression cylinder contact area has helped identify higher printing pressure differences in the form of ink density. Being a quantitative approach the ink density data is also useful to produce statistical information and apply principles of statistical process control. This experimental works also provided information to help printer assess the performance of bearings and other mechanical elements used in blanket and impression cylinder mechanisms.

\section{REFERENCES}

[1] Agnieszka, J. (2014). The change of printout's quality depending on pressure of a blanket cylinder against an impression cylinder and a plate cylinder in offset machine. ActaMechanica Automatic, 8, pp. 9-15.

[2] Rastko, M. (2014).Influence of different printing pressure levels on sheet-fed offset print quality. $J$ Chem Tech and Metallurgy,49, pp. 375-382.

[3] Agnieszka, J. Analysis of pressure force between two cylinders. Mechanics, Automation and Robotics, [online] p. 10-20. Available at: http://yadda. icm.edu.pl/yadda/element/bwmeta 1.element. baztech-b8e5a339-7655-43e4-bb89-7888c0b9f837/ c/Jurkiewicz.pdf [Accessed 20 May 2019].

[4] Rastko, M. (2013),.Investigation of the printing pressure level application influence on sheet-fed offset print quality. Machine Desg, 5, pp.171-176.
[5] (2012),.Stabilizing the offset process cylinder pressure. Rolf Hansson Consulting. [online] p.1:4.Available at:http://www.igt.com.sg/resources/ content/files/offset-cylinder-pressure.pdf[Accessed 20 May 2019].

[6] Junghong. Guo (2011). Kinematics Analysis of onOff Pressure Mechanism with Flexible Link for Offset Press, Applied Mechanics and Materials, Vol. 120 , pp. 321-324

[7] Shuqin, W.(2009).Research on the Methods of the Measurement of Printing Pressure in Offset Press. InInternational Conference on Measuring Technology and Mechatronics Automation. [online]Zhangjiajiepp. 342-344Available at: https:/ / i e e ex p lor e.i e e e org / d o c u m en t / 5202981 ?arnumber $=5202981$ [Accessed 20 May 2019].

[8] Helmut, K., (2008). Handbook of Print Media. Springerpp 5-25

[9] Yung-C. (1997).An investigation of the factors affecting dot gain on sheet-fed offset lithography presses. Iwoa State University,pp. 58:70

[10] Alexander M.(1991), The Effects of blanket tension and squeeze pressure on slur and doubling using conventional and compressible blankets in sheetfed offset lithography . Rochester Institute of Technology RIT Scholar Works. pp. 33:50

[11] Hong-guang, S. (2016),Effects of Offset Printing Pressure on Ink Transfer Performance. Packaging Engineering, pp. 1

[12] Menges M. (1995)The basic theory of crowing engineering rollers.[online] pp. 1-8Avaliable at: h t t p ://www. maxcessint 1 . com/mengesroller[Accessed 20 May 2019]. 
Appendix: A

Observed row-wise densities of patches from 102th, 502th and $902^{\text {nd }}$ sheets.

\begin{tabular}{|c|c|c|c|c|c|c|c|c|c|}
\hline \multirow[b]{2}{*}{ 离 } & \multicolumn{3}{|c|}{ Sheet No 102} & \multicolumn{3}{|c|}{ Sheet No 502} & \multicolumn{3}{|c|}{ Sheet No 902} \\
\hline & $\begin{array}{c}\text { Density } \\
\text { on } \\
\text { Row-1 }\end{array}$ & $\begin{array}{c}\text { Density } \\
\text { on } \\
\text { Row-11 }\end{array}$ & $\begin{array}{c}\text { Density } \\
\text { on } \\
\text { Row-22 }\end{array}$ & $\begin{array}{c}\text { Density } \\
\text { on } \\
\text { Row-1 }\end{array}$ & $\begin{array}{c}\text { Density } \\
\text { on } \\
\text { Row-11 }\end{array}$ & $\begin{array}{c}\text { Density } \\
\text { on } \\
\text { Row-22 }\end{array}$ & $\begin{array}{c}\text { Density } \\
\text { on } \\
\text { Row-1 }\end{array}$ & $\begin{array}{c}\text { Density } \\
\text { on } \\
\text { Row-11 }\end{array}$ & $\begin{array}{c}\text { Density } \\
\text { on } \\
\text { Row-22 }\end{array}$ \\
\hline 1 & 1.55 & 1.43 & 1.47 & 1.52 & 1.48 & 1.46 & 1.47 & 1.50 & 1.48 \\
\hline 2 & 1.52 & 1.50 & 1.50 & 1.44 & 1.46 & 1.43 & 1.43 & 1.45 & 1.42 \\
\hline 3 & 1.48 & 1.46 & 1.47 & 1.46 & 1.45 & 1.47 & 1.42 & 1.44 & 1.41 \\
\hline 4 & 1.48 & 1.47 & 1.45 & 1.47 & 1.44 & 1.42 & 1.43 & 1.45 & 1.38 \\
\hline 5 & 1.50 & 1.49 & 1.46 & 1.45 & 1.44 & 1.44 & 1.42 & 1.44 & 1.40 \\
\hline 6 & 1.51 & 1.51 & 1.49 & 1.51 & 1.48 & 1.47 & 1.43 & 1.45 & 1.47 \\
\hline 7 & 1.55 & 1.55 & 1.53 & 1.52 & 1.51 & 1.50 & 1.47 & 1.50 & 1.48 \\
\hline 8 & 1.54 & 1.54 & 1.50 & 1.53 & 1.48 & 1.44 & 1.48 & 1.49 & 1.48 \\
\hline 9 & 1.57 & 1.55 & 1.55 & 1.54 & 1.51 & 1.43 & 1.50 & 1.51 & 1.49 \\
\hline 10 & 1.58 & 1.57 & 1.57 & 1.55 & 1.51 & 1.49 & 1.53 & 1.50 & 1.51 \\
\hline 11 & 1.56 & 1.55 & 1.54 & 1.52 & 1.49 & 1.48 & 1.48 & 1.48 & 1.47 \\
\hline 12 & 1.54 & 1.53 & 1.51 & 1.46 & 1.45 & 1.44 & 1.47 & 1.46 & 1.47 \\
\hline 13 & 1.54 & 1.53 & 1.54 & 1.47 & 1.45 & 1.46 & 1.47 & 1.43 & 1.43 \\
\hline 14 & 1.50 & 1.52 & 1.47 & 1.45 & 1.42 & 1.38 & 1.41 & 1.39 & 1.41 \\
\hline 15 & 1.53 & 1.52 & 1.49 & 1.44 & 1.40 & 1.42 & 1.45 & 1.42 & 1.39 \\
\hline 16 & 1.54 & 1.54 & 1.53 & 1.51 & 1.47 & 1.44 & 1.52 & 1.51 & 1.48 \\
\hline 17 & 1.55 & 1.54 & 1.52 & 1.51 & 1.47 & 1.47 & 1.50 & 1.48 & 1.47 \\
\hline 18 & 1.54 & 1.51 & 1.49 & 1.48 & 1.44 & 1.45 & 1.45 & 1.45 & 1.47 \\
\hline 19 & 1.51 & 1.52 & 1.51 & 1.47 & 1.46 & 1.46 & 1.44 & 1.46 & 1.44 \\
\hline 20 & 1.52 & 1.52 & 1.48 & 1.46 & 1.44 & 1.43 & 1.42 & 1.43 & 1.44 \\
\hline 21 & 1.50 & 1.51 & 1.51 & 1.46 & 1.41 & 1.45 & 1.41 & 1.42 & 1.43 \\
\hline 22 & 1.49 & 1.51 & 1.48 & 1.42 & 1.40 & 1.38 & 1.40 & 1.44 & 1.41 \\
\hline 23 & 1.52 & 1.51 & 1.52 & 1.46 & 1.42 & 1.49 & 1.43 & 1.46 & 1.41 \\
\hline 24 & 1.53 & 1.50 & 1.49 & 1.47 & 1.42 & 1.43 & 1.43 & 1.45 & 1.42 \\
\hline 25 & 1.55 & 1.52 & 1.55 & 1.48 & 1.44 & 1.45 & 1.44 & 1.54 & 1.46 \\
\hline 26 & 1.55 & 1.54 & 1.58 & 1.51 & 1.46 & 1.50 & 1.46 & 1.45 & 1.50 \\
\hline 27 & 1.55 & 1.59 & 1.58 & 1.53 & 1.52 & 1.53 & 1.48 & 1.44 & 1.53 \\
\hline 28 & 1.53 & 1.58 & 1.55 & 1.52 & 1.52 & 1.55 & 1.44 & 1.45 & 1.49 \\
\hline 29 & 1.48 & 1.51 & 1.58 & 1.44 & 1.47 & 1.52 & 1.41 & 1.40 & 1.44 \\
\hline 30 & 1.48 & 1.51 & 1.55 & 1.46 & 1.45 & 1.5 & 1.41 & 1.37 & 1.44 \\
\hline 31 & 1.40 & 1.55 & 1.5 & 1.45 & 1.48 & 1.48 & 1.40 & 1.35 & 1.47 \\
\hline 32 & 1.46 & 1.50 & 1.51 & 1.46 & 1.46 & 1.53 & 1.43 & 1.41 & 1.47 \\
\hline 33 & 1.49 & 1.54 & 1.53 & 1.49 & 1.46 & 1.49 & 1.47 & 1.47 & 1.46 \\
\hline 34 & 1.51 & 1.57 & 1.57 & 1.49 & 1.48 & 1.47 & 1.57 & 1.48 & 1.46 \\
\hline 35 & 1.58 & 1.54 & 1.51 & 1.52 & 1.46 & 1.48 & 1.53 & 1.55 & 1.51 \\
\hline
\end{tabular}




\section{Appendix: B}

Observed column-wise densities of patches from 102nd, 502th and 902nd sheets.

\begin{tabular}{|c|c|c|c|c|c|c|c|c|c|}
\hline \multirow[b]{2}{*}{ 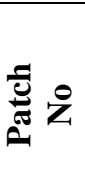 } & \multicolumn{3}{|c|}{ Sheet No 102} & \multicolumn{3}{|c|}{ Sheet No 502} & \multicolumn{3}{|c|}{ Sheet No 902} \\
\hline & $\begin{array}{c}\text { Density } \\
\text { on } \\
\text { Col.1 }\end{array}$ & $\begin{array}{c}\text { Density } \\
\text { on } \\
\text { Col.17 }\end{array}$ & $\begin{array}{c}\text { Density } \\
\text { on } \\
\text { Col.35 }\end{array}$ & $\begin{array}{c}\text { Density } \\
\text { on } \\
\text { Col.1 }\end{array}$ & $\begin{array}{c}\text { Density } \\
\text { on } \\
\text { Col.17 }\end{array}$ & $\begin{array}{c}\text { Density } \\
\text { on } \\
\text { Col.35 }\end{array}$ & $\begin{array}{c}\text { Density } \\
\text { on } \\
\text { Col.1 }\end{array}$ & $\begin{array}{c}\text { Density } \\
\text { on } \\
\text { Col.17 }\end{array}$ & $\begin{array}{c}\text { Density } \\
\text { on } \\
\text { Col.35 }\end{array}$ \\
\hline 1 & 1.50 & 1.49 & 1.54 & 1.50 & 1.47 & 1.53 & 1.43 & 1.44 & 1.52 \\
\hline 2 & 1.53 & 1.50 & 1.54 & 1.47 & 1.46 & 1.52 & 1.42 & 1.45 & 1.56 \\
\hline 3 & 1.51 & 1.49 & 1.50 & 1.46 & 1.45 & 1.47 & 1.46 & 1.43 & 1.47 \\
\hline 4 & 1.50 & 1.49 & 1.51. & 1.50 & 1.45 & 1.48 & 1.48 & 1.47 & 1.53 \\
\hline 5 & 1.48 & 1.51 & 1.53 & 1.50 & 1.46 & 1.49 & 1.44 & 1.45 & 1.50 \\
\hline 6 & 1.51 & 1.52 & 1.54 & 1.50 & 1.46 & 1.50 & 1.47 & 1.44 & 1.52 \\
\hline 7 & 1.53 & 1.54 & 1.55 & 1.54 & 1.45 & 1.54 & 1.43 & 1.45 & 1.51 \\
\hline 8 & 1.15 & 1.48 & 1.58 & 1.51 & 1.44 & 1.52 & 1.47 & 1.43 & 1.51 \\
\hline 9 & 1.56 & 1.50 & 1.54 & 1.48 & 1.45 & 1.52 & 1.45 & 1.41 & 1.52 \\
\hline 10 & 1.48 & 1.48 & 1.49 & 1.49 & 1.46 & 1.53 & 1.47 & 1.44 & 1.52 \\
\hline 11 & 1.48 & 1.51 & 1.53 & 1.52 & 1.44 & 1.46 & 1.50 & 1.43 & 1.47 \\
\hline 12 & 1.50 & 1.50 & 1.50 & 1.47 & 1.43 & 1.49 & 1.47 & 1.44 & 1.44 \\
\hline 13 & 1.47 & 1.51 & 1.52 & 1.50 & 1.42 & 1.49 & 1.47 & 1.44 & 1.43 \\
\hline 14 & 1.52 & 1.50 & 1.53 & 1.50 & 1.45 & 1.49 & 1.47 & 1.43 & 1.49 \\
\hline 15 & 1.48 & 1.50 & 1.54 & 1.52 & 1.45 & 1.53 & 1.45 & 1.43 & 1.46 \\
\hline 16 & 1.47 & 1.49 & 1.56 & 1.51 & 1.44 & 1.52 & 1.45 & 1.44 & 1.51 \\
\hline 17 & 1.44 & 1.49 & 1.57 & 1.49 & 1.42 & 1.52 & 1.46 & 1.43 & 1.53 \\
\hline 18 & 1.44 & 1.50 & 1.57 & 1.52 & 1.45 & 1.51 & 1.44 & 1.45 & 1.55 \\
\hline 19 & 1.49 & 1.49 & 1.57 & 1.52 & 1.45 & 1.53 & 1.47 & 1.45 & 1.49 \\
\hline 20 & 1.46 & 1.48 & 1.49 & 1.49 & 1.44 & $1 . .44$ & 1.46 & 1.40 & 1.46 \\
\hline 21 & 1.52 & 1.52 & 1.49 & 1.51 & 1.44 & 1.51 & 1.50 & 1.44 & 1.49 \\
\hline 22 & 1.45 & 1.45 & 1.52 & 1.46 & 1.45 & 1.48 & 1.46 & 1.46 & 1.49 \\
\hline
\end{tabular}

